Article

\title{
Overexpression of Exosomal Cardioprotective miRNAs Mitigates Hypoxia-Induced H9c2 Cells Apoptosis
}

\author{
Jinwei Zhang ${ }^{\dagger}$, Jideng Ma ${ }^{\dagger}$, Keren Long ${ }^{\dagger}$, Wanling Qiu, Yujie Wang, Zihui Hu, Can Liu, Yi Luo, \\ Anan Jiang, Long Jin, Qianzi Tang, Xun Wang, Xuewei Li * and Mingzhou Li *
}

Institute of Animal Genetics and Breeding, College of Animal Science and Technology, Sichuan Agricultural University, Chengdu 611130, Sichuan, China; Jinweizhang50@163.com (J.Z.); jideng_ma@sina.com (J.M.); longkeren@163.com (K.L.); qiuwanling2016@163.com (W.Q.); wangyujie715@163.com (Y.W.); Huzihui2016@163.com (Z.H.); 18227550880@163.com (C.L.); luoyi670@163.com (Y.L.); lingdang317@163.com (A.J.); longjin8806@163.com (L.J.); wupie@163.com (Q.T.); xun_wang007@163.com (X.W.)

* Correspondence: xuewei.li@sicau.edu.cn (X.L.); mingzhou.li@163.com (M.L.); Tel./Fax: +86-28-8629-0998 (X.L.); +86-28-8629-0962 (M.L.)

+ These authors contributed equally to this work.

Academic Editor: Y-h. Taguchi

Received: 10 February 2017; Accepted: 24 March 2017; Published: 28 March 2017

\begin{abstract}
Recent evidence suggests that hypoxia caused by acute myocardial infarction can induce cardiomyocyte apoptosis. Exosomes are signalling mediators that contribute to intercellular communication by transporting cytosolic components including miRNAs, mRNAs, and proteins. However, the systemic regulation and function of exosomal miRNAs in hypoxic cardiomyocytes are currently not well understood. Here, we used small RNA sequencing to investigate the effects of hypoxia stress on miRNAome of rat cardiomyoblast cells (H9c2) and corresponding exosomes. We identified 92 and 62 miRNAs in cells and exosomes, respectively, that were differentially expressed between hypoxia and normoxia. Hypoxia strongly modulated expression of hypoxia-associated miRNAs in $\mathrm{H} 9 \mathrm{c} 2$ cells, and altered the miRNAome of H9c2 cells-derived exosomes. Functional enrichment analysis revealed extensive roles of differentially expressed exosomal miRNAs in the HIF-1 signalling pathway and in apoptosis-related pathways including the TNF, MAPK, and mTOR pathways. Furthermore, gain- and loss-of-function analysis demonstrated potential anti-apoptotic effects of the hypoxia-induced exosomal miRNAs, including miR-21-5p, miR-378-3p, miR-152-3p, and let-7i-5p; luciferase reporter assay confirmed that Atg12 and Faslg are targets of miR-152-3p and let-7i-5p, respectively. To summarize, this study revealed that hypoxia-induced exosomes derived from $\mathrm{H} 9 \mathrm{c} 2$ cells loaded cardioprotective miRNAs, which mitigate hypoxia-induced H9c2 cells apoptosis.
\end{abstract}

Keywords: H9c2 cells; microRNA; exosome; apoptosis; hypoxia

\section{Introduction}

Acute myocardial infarction (AMI), a common consequence of coronary artery occlusion and myocardial ischemia, is one of the leading causes of death worldwide [1,2]. Hypoxia caused by AMI leads to cardiomyocyte apoptosis [3]. Unlike necrosis, apoptosis is a process of programmed cell death that is actively controlled by a series of genes to maintain homeostasis [4]. Hypoxia-inducible factor (HIF), which comprises $\alpha$ and $\beta$ subunit, is a master regulator of cellular response to hypoxia [5]. Under hypoxic conditions, HIF- $\alpha$ (HIF- $1 \alpha$, HIF- $2 \alpha$ and HIF- $3 \alpha$ ) is activated and translocates from the cytoplasm to the nucleus, where it dimerizes with HIF- $\beta$ and binds to hypoxia response elements 
(HRE) in the promoters of HIF-controlled genes [6]. Afterward, hypoxia-adaptive pathways will be activated, including angiogenesis, anaerobic metabolism, erythropoiesis, and iron metabolism, to reduce oxygen consumption and increase cell survival [7]. Nonetheless, continuous hypoxic stress will eventually lead to apoptosis, or even necrosis [8].

miRNA, a class of endogenous non-coding RNA, is well established as a mediator of post-transcriptional regulation in a wide array of biological processes, including differentiation, proliferation and apoptosis [9]. Recently, a number of studies have demonstrated that hypoxia can modulate expression of a specific subset of miRNAs, termed "hypoxamiRs"; and that these hypoxamiRs coordinate HIF signaling to regulate cell proliferation, metabolism, DNA repair, and apoptosis [10]. Exosomes are nano-sized (50-200 $\mathrm{nm}$ ) vesicles released by many cell types via exocytosis. They can mediate cell-to-cell communication and function as signalling agents by delivering nucleic acids (including miRNA and mRNA) and proteins between cells [11]. Emerging evidence indicates that exosome-mediated transfer of miRNAs between cardiomyocytes contributes to reconciling cardiac physiology and pathology state. Cardiac fibroblast-derived exosomes deliver miR-21* to cardiomyocytes to induce myocardial hypertrophy by targeting SORBS2 and PDLIM5 [12]. miR-21-5p and miR-210-3p are enriched in exosomes secreted from mouse cardiac fibroblast-derived induced pluripotent stem cells (iPS cells), and prevent H9c2 cells apoptosis by regulating Nanog and HIF- $1 \alpha$, respectively [13]. miR-210-3p derived from exosomes secreted by cardiac progenitor cells (CPCs) inhibits cardiomyocyte apoptosis by targeting ephrin A3 and PTP1b [14]. However, the systemic regulation and function of exosomal miRNA in cardiomyocytes under AMI-induced hypoxic stress are poorly understood.

In this study, we established a model of anoxia using H9c2 cells, an immortal rat cardiomyoblast cell line, in hypoxic conditions that mimicked the hypoxia caused by AMI in vitro. We used small RNA sequencing to investigate the miRNA transcriptome of H9c2 cells and exosomes collected from hypoxia and normoxia. We found that expression of hypoxamiRs was strongly regulated by hypoxia in $\mathrm{H} 9 \mathrm{c} 2$ cells; furthermore, hypoxia markedly altered the miRNAome of H9c2 cells-derived exosomes. The exosomal miRNAs that were differentially expressed (DE miRNAs) between hypoxia and normoxia were mainly involved in the HIF-1 signaling pathway and cell apoptosis. Our results reveal that exosomes produced by $\mathrm{H} 9 \mathrm{c} 2$ cells in response to hypoxia contain cardioprotective miRNAs and mitigate H9c2 cells apoptosis after hypoxia, which may present a potential novel treatment for AMI and other types of heart disease.

\section{Results and Discussion}

\subsection{Hypoxia Decreases Cell Viability and Induces Apoptosis in H9c2 Cells}

A previous study demonstrated that hypoxia induced cardiomyocyte apoptosis, which was involved in the pathogenesis of AMI [15]. To illustrate the physiological effect of acute hypoxia on $\mathrm{H} 9 \mathrm{c} 2$ cells, we cultured $\mathrm{H} 9 \mathrm{c} 2$ cells in vitro under hypoxic conditions $\left(1 \% \mathrm{O}_{2}\right)$ for $48 \mathrm{~h}$. Hypoxia induced notable changes in cell morphology and growth, and induced H9c2 cell apoptosis (Figure 1A). Furthermore, CCK8 (Figure 1B) and flow cytometry analysis (Figure 1D,E) indicated that hypoxia significantly reduced $\mathrm{H} 9 \mathrm{c} 2$ cell viability and induced apoptosis, in keeping with previous studies $[16,17]$. Additionally, we analysed cell membrane integrity by LDH release assay, which showed a higher LDH leakage rate in hypoxia compared with normoxia (Figure 1C). Furthermore, hypoxia markedly increased expression of the pro-apoptotic genes Caspase-3, Bax, Aaf-1, Faslg, and P53, whereas expression of the anti-apoptotic gene $B c l-2$ was inhibited by hypoxia (Figure 1F). These results indicate that, as expected, hypoxia induced $\mathrm{H} 9 \mathrm{c} 2$ cells apoptosis. 

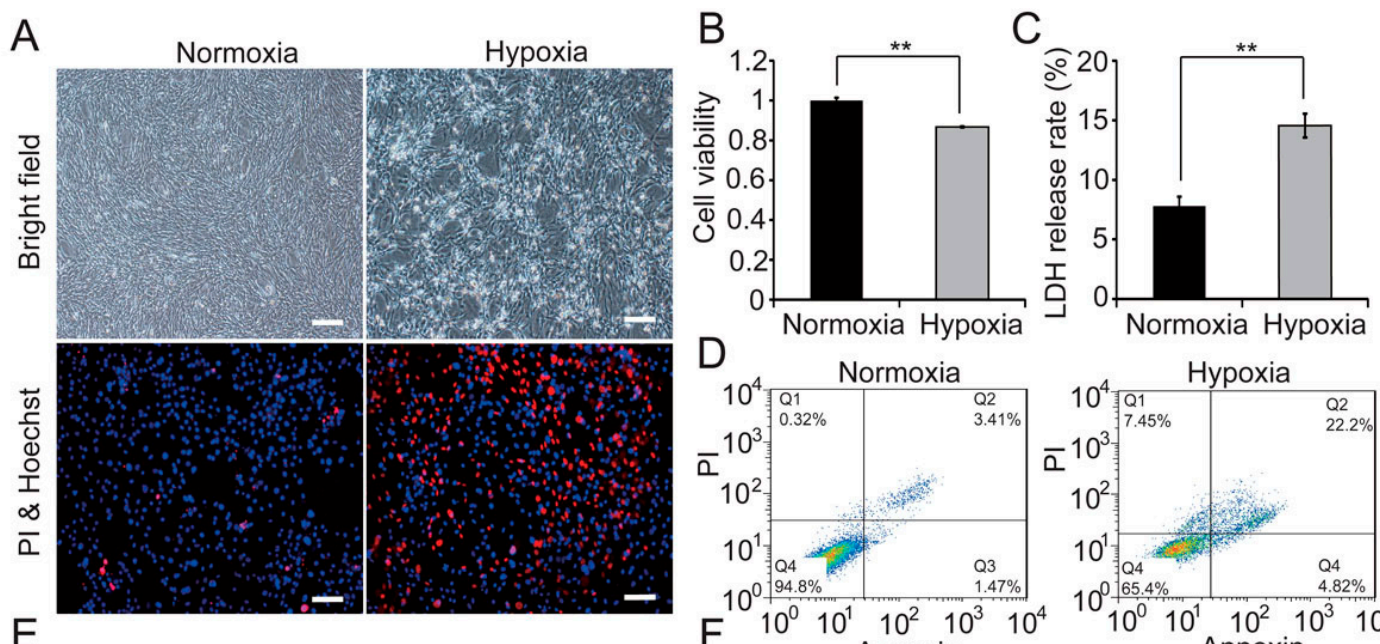

$\mathrm{E}$
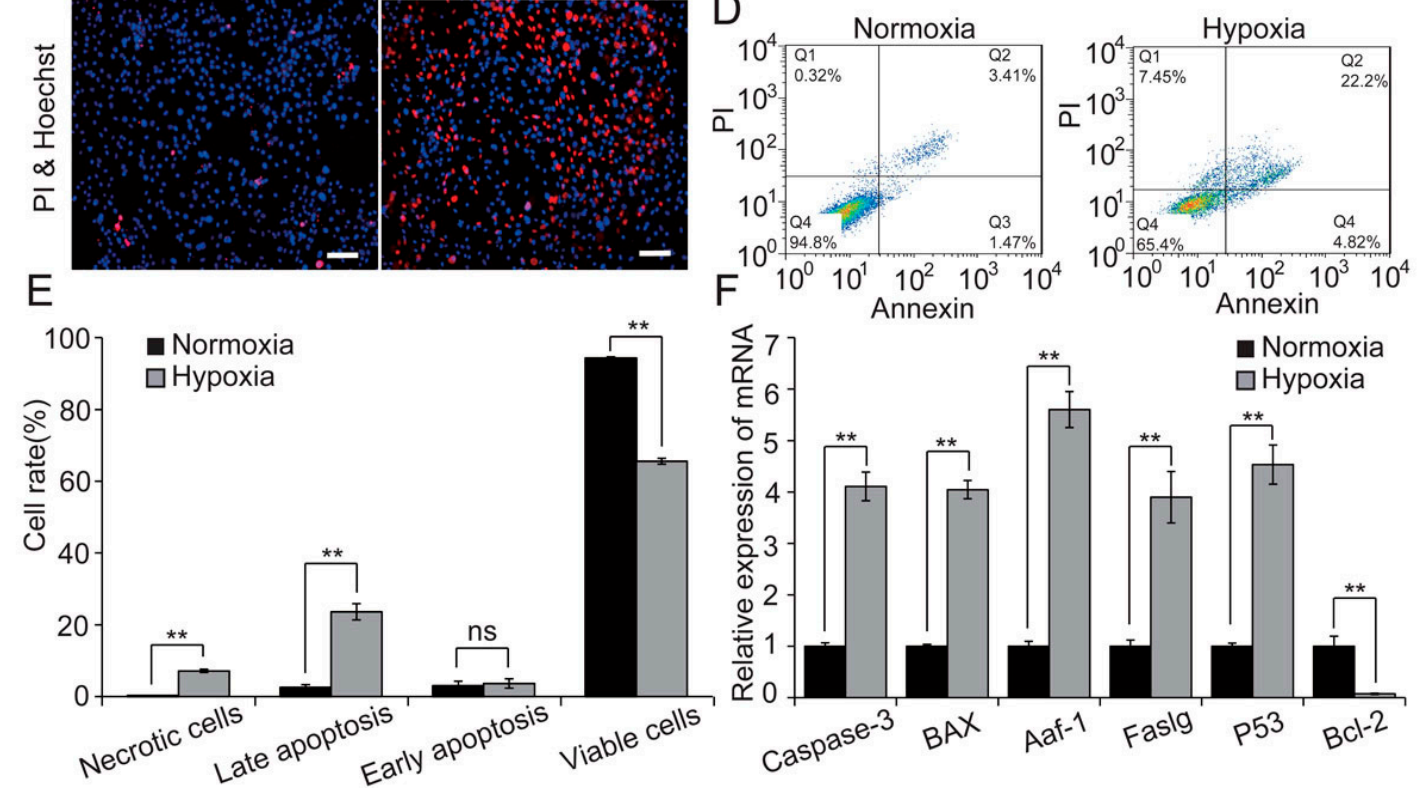

Figure 1. Hypoxia induced $\mathrm{H} 9 \mathrm{c} 2$ cells apoptosis. (A) H9c2 cells were exposed to hypoxia or normoxia for $48 \mathrm{~h}$ then observed by bright-field microscopy, and by fluorescence microscopy with propidium iodide (PI) and Hoechst 33324 double-staining. Scale bar, $10 \mu \mathrm{m}$; cell viability (B), membrane integrity (C) and apoptosis rate (D,E) were evaluated by CCK8 assay, LDH release assay and flow cytometry analysis, respectively; and (F) expression levels of apoptosis-related genes were detected by qRT-PCR. Three independent experiments performed in triplicate; all data are expressed as mean \pm SD. ${ }^{* *} p<0.01$, ns: no significant.

\subsection{Hypoxia Significantly Modulates hypoxamiR Levels in H9c2 Cells}

Hypoxia modulates expression of hypoxamiRs, which can directly and indirectly regulate hypoxia-adaptive pathways to preserve cell viability [7]. To comprehensively explore hypoxia-induced variations in the miRNA transcriptome, $\mathrm{H} 9 \mathrm{c} 2$ cells were cultured in normoxic and hypoxic conditions, then collected and prepared for Illumina small RNA-seq. We identified 338 and 331 known miRNAs in normoxic and hypoxic $\mathrm{H} 9 \mathrm{c} 2$ cells, respectively. The number of overlapping and unique miRNAs in normoxic and hypoxic H9c2 cells is shown in Figure 2A. Overlapping miRNAs account for $89.5 \%$ of the total, which shows that hypoxia induced a small change in the miRNA species. Afterwards, 92 differentially-expressed miRNAs were identified in H9c2 cells after hypoxia (defined as those exhibiting a fold-change between hypoxic and normoxic conditions of $<0.5$ or $>2$ ) (Table S1). Notably, the distribution of miRNAs showed that more than half of the known hypoxamiRs ( 31 of $60,51.67 \%$ ) were presented in the DE miRNAs of cells after hypoxia, which indicated that hypoxia significantly modulated the hypoxamiRs expression in H9c2 cells ( $p=9.99 \times 10^{-11}, \chi^{2}$-test; Figure 2B). Additionally, we randomly selected seven miRNAs for validation of expression; the results demonstrated high correlation between the small RNA-seq and qRT-PCR (Figure 2C). Most of the DE miRNAs in cells have functions related to the cellular response to hypoxia. For example, miR-210-3p is known as the "master" hypoxamiR; it is induced by hypoxia in a HIF-dependent manner and has been 
shown to exhibit cardioprotective effects, such as preservation of cardiac function, upregulation of neovascularization, and inhibition of apoptosis [18]. Moreover, miR-351-5p directly target Ang-2 and VEGF and has been shown to participate in hypoxia-induced microvascular dysfunction [19]. miR-199a-5p is acutely downregulated in cardiac myocytes after hypoxia and directly targets HIF-1 $\alpha$ and Sirtuin 1 to regulate the hypoxia-triggered pathway, it can be exploited for preconditioning cells against hypoxic damage [20].

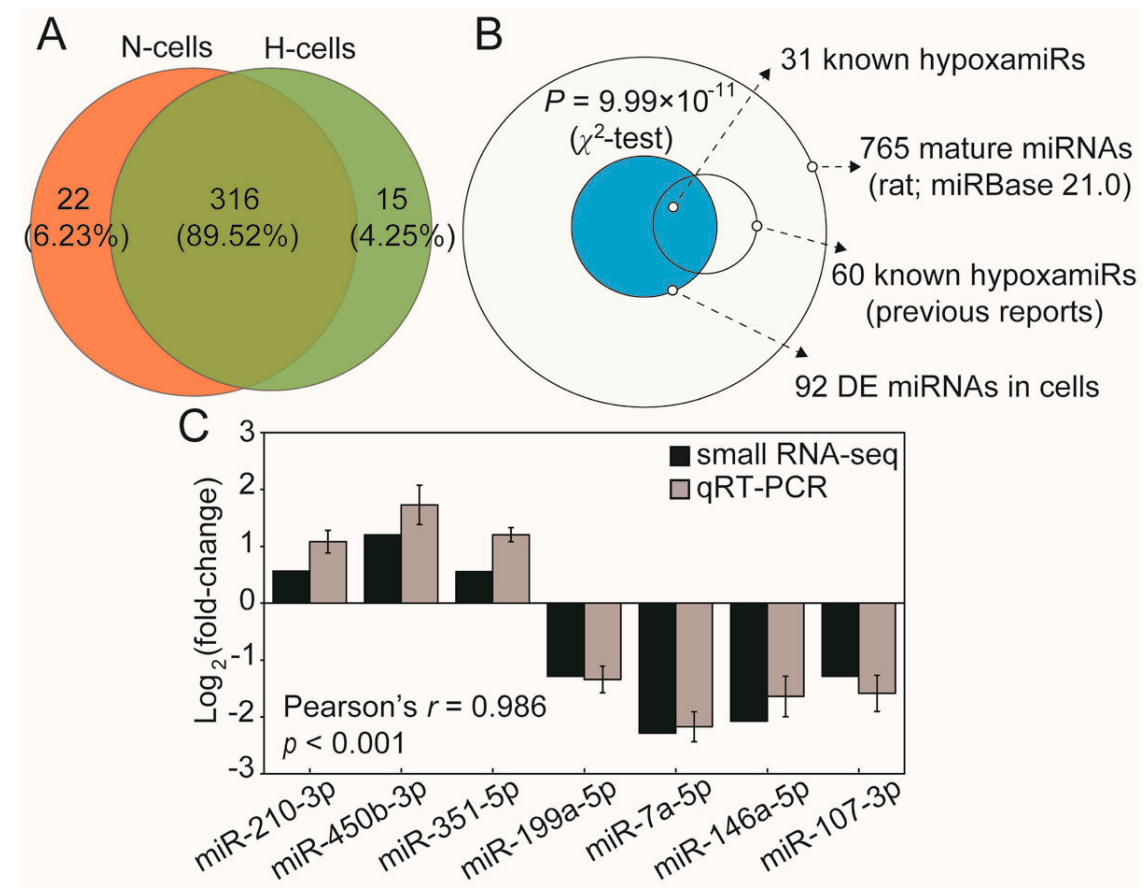

Figure 2. miRNA expression profiles of normoxic and hypoxic H9c2 cells. (A) Venn diagram showing the numbers of overlapping and unique miRNAs detected in normoxic and hypoxic H9c2 cells; (B) Distribution of miRNAs. Out of 765 rat mature miRNAs deposited in miRBase 21.0, $60(7.84 \%)$ miRNAs have been designated as hypoxamiRs based on the previous reports $[7,10]$, and the hypoxamiRs (31 of 92, 33.69\%) were overrepresented in the DE miRNAs of cells after hypoxia

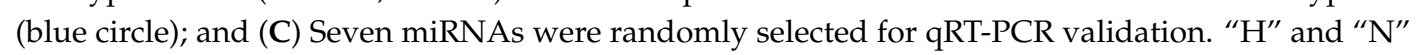
represented "Hypoxia" and "Normoxia", respectively.

\subsection{Hypoxia Dramatically Alters the miRNAome of H9c2 Cells-Derived Exosomes}

Recent reports have shown that exosomes are produced by many cardiac-derived cell types, including cardiac fibroblasts [12], cardiac fibroblast-derived induced pluripotent stem cells [13], and cardiac progenitor cells [14]; these exosomes can play important roles in intercellular communication. We isolated exosomes from the culture media of $\mathrm{H} 9 \mathrm{c} 2$ cells cultured under normoxic and hypoxic conditions by ultracentrifugation. The sizes distribution of the particles were investigated using NanoSight, a nanoparticle tracking analyser, which revealed particles ranging from 50 to $200 \mathrm{~nm}$ in diameter (Figure 3A), in keeping with typical exosome size [21,22]. Although the size range of exosomes were similar to normoxia group, the area under the curve of hypoxia group was increased, which indicated that hypoxia increased the number of exosomes secreted. Recent reports have suggested that some in vitro environmental stressors, such as heat [23], hypoxia [23,24], and glucose starvation [25], can enhance the secretion and modify the composition of exosomes in various cell types, including 3T3-L1 adipocytes [25], and cardiac progenitor cells [26]. Furthermore, we found that for both normoxia and hypoxia, total RNA isolated from $\mathrm{H} 9 \mathrm{c} 2$ cells-derived exosomes contained a considerable number of small RNAs of approximately 25 nucleotides in length (Figure S1). These results showed that $\mathrm{H} 9 \mathrm{c} 2$ cells produced miRNA-enriched exosomes under both normoxia and hypoxia. 


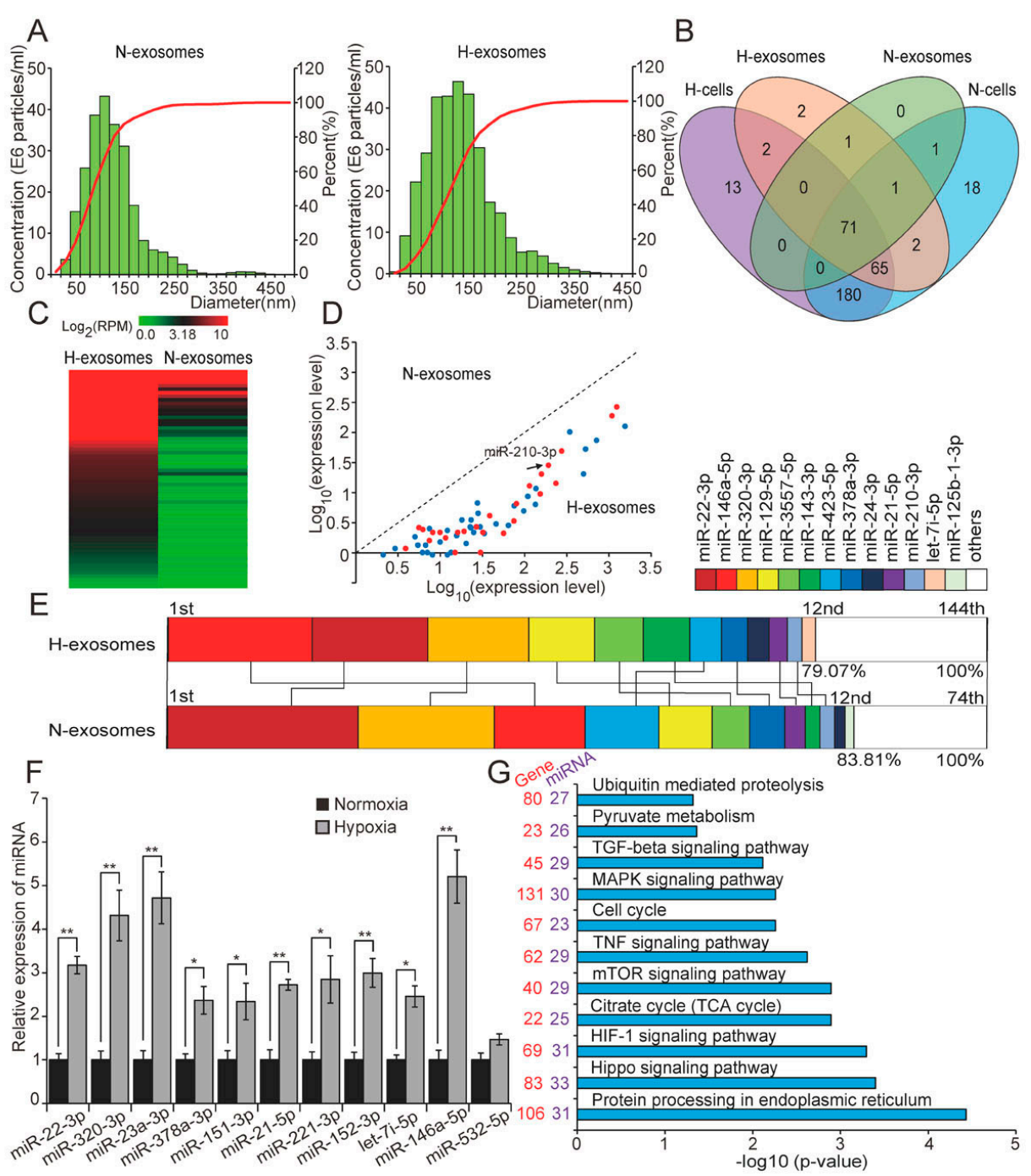

Figure 3. H9c2 cells-derived exosomal miRNAome was dramatically altered by hypoxia. (A) Particle size distribution in purified exosomes was measured by NanoSight Tracking Analyzer; (B) Venn diagram representing the numbers of miRNAs between H9c2 cells and exosomes before and after hypoxia; this revealed significant hypoxia-induced changes in the miRNAome of H9C2-derived exosomes; heatmap (C) and scatter diagram (D) showing the DE miRNAs (fold change $<0.5$ or $>2$ between hypoxia and normoxia) in exosomes; all of these DE miRNAs were upregulated in hypoxia compared with in normoxia; red dots represented known hypoxamiRs (arrow indicated miR-210-3p); (E) the 12 unique miRNAs with the highest expression levels in hypoxic and normoxic exosome miRNA libraries; this indicated that hypoxia significantly altered the ranking of the miRNAs within the list; (F) validation of small RNA-seq using qRT-PCR; and (G) gene ontology categories and pathways enriched for target genes of DE miRNAs in hypoxic exosomes. $p$-Values, which indicates the significance of the enrichment, were calculated by Benjamini-corrected modified Fisher's exact test. "H" and "N" represented "Hypoxia" and "Normoxia", respectively. All data are expressed as mean \pm SD. ${ }^{*} p<0.05,{ }^{* *} p<0.01$.

Previously, Valadi et al. [11] suggested that miRNA-loaded exosomes can deliver their contents to other cell types and, thus, act as signaling mediators and exert functional regulation. To examine the miRNAome difference of $\mathrm{H} 9 \mathrm{c} 2$ cells-derived exosomes under both normoxia and hypoxia, we conducted small RNA-seq analysis using total RNA isolated from the exosomes. This analysis identified 74 and 144 known miRNAs in normoxic and hypoxic H9c2 cells-derived exosomes, respectively. Notably, comparing the slight difference of miRNA species in cells, hypoxia manifestly 
increased miRNA species in exosomes (Figures 2A and 3B). Interestingly, all of the DE miRNAs in exosomes (62 in total; fold-change $<0.5$ or $>2$; Table S2) were upregulated in hypoxia compared with in normoxia, and included a number of known hypoxamiRs (Figure 3C,D). These results showed that hypoxia altered both the types and expression levels of miRNAs in H9c2 cells-derived exosomes. Moreover, the 12 unique miRNAs with the highest expression levels accounted for $79.07 \%$ and $83.81 \%$ by total read counts of all miRNAs in hypoxic and normoxic exosomes, respectively. Meanwhile, 11 of the 12 most highly-expressed unique miRNAs were shared between normoxic and hypoxic exosomes, but their ranks in terms of expression levels obviously differed between the two conditions (Figure 3E). These results further demonstrated that hypoxia markedly changed the miRNAome of H9c2 cells-derived exosomes. Additionally, 11 miRNAs were randomly selected for qRT-PCR validation (Figure 3F).

To explore the potential functions of the DE miRNAs in hypoxic exosomes, we conducted target prediction and functional enrichment analysis using DIANA online software [27]. This revealed that the target genes of DE miRNAs in hypoxic exosomes were mainly involved in the HIF-1 signalling pathway, the cell cycle, or pathways involved in cell apoptosis, including the hippo, mTOR, TNF, MAPK, and TGF- $\beta$ signalling pathways (Figure 3G), all of which are highly relevant to the hypoxic adaptability of cells. Notably, half of the DE miRNAs that we identified $(31 / 62,50 \%)$ were enriched in the HIF-1 signalling pathway; these hypoxamiRs directly target important mRNA transcripts that coordinate metabolic reprogramming, apoptosis, survival, and many other cellular processes that contribute to hypoxia adaptation. Additionally, some of DE miRNAs were enriched in functional processes related to cell viability under hypoxia, such as the TNF, MAPK, and mTOR signalling pathways. TNF family proteins, especially TNF- $\alpha$, can activate multiple cell death pathways that contribute to progressive cardiomyocyte apoptosis [28,29]. The MAPK signalling pathway, which includes ERK1/2, JNK, and P38, plays an important role in cell proliferation, differentiation, and apoptosis [30]. Activation of JNK or p38 MAP kinases induces apoptosis in various cell types [31], including cardiomyocytes [32]. ERK1/2 exerts bidirectional effects in apoptosis, activation of ERK1/2, can activate or inhibit downstream effectors to determine cell fate [33]; acute activation of ERK1/2, exerts an anti-apoptotic effect and, thus, mitigates myocardial ischemia reperfusion injury (I/R injury), whereas chronic activation of ERK1/2 causes cardiomyocyte hypertrophy and is an essential mechanistic molecular pathway in adverse cardiac remodeling [34]. mTOR also has pleiotropic functions in the regulation of cell apoptosis; it can act as an inhibitor or an inducer of apoptosis depending on the cellular context [35]. Moreover, some of the DE miRNAs identified were enriched in the citrate cycle (the TCA cycle), pyruvate metabolism, ubiquitin mediated proteolysis, which suggests that hypoxia may affect the metabolism of glucose and some proteins.

\subsection{Overexpression of Hypoxia-Induced Exosomal miRNAs Mitigates Hypoxia-Induced Apoptosis}

To further investigate the biological function of hypoxia-induced exosomal miRNAs in H9c2 cell apoptosis, we selected miR-21-5p, miR-378-3p, miR-152-3p, and let-7i-5p, which were significantly upregulated in hypoxic exosomes and participated in apoptosis, for functional verification. Among these miRNAs, miR-21-5p, and miR-378-3p have been reported to have anti-apoptotic effects in cardiomyocytes under hypoxic stress [36,37]. Gain- and loss-of-function analyses were performed using transfection of miRNA mimic (or mimic control), or inhibitor (or inhibitor control). qRT-PCR confirmed effective overexpression and downregulation of miRNAs in H9c2 cells transfected with the mimic and inhibitor, respectively (Figure 4A). Cells were exposed to hypoxia for $48 \mathrm{~h}$ after transfection, then cell viability, membrane integrity, and apoptosis rate were evaluated. As a result, under hypoxia condition, overexpression of miR-21-5p significantly suppressed the reduction of cell viability $(p<0.05$; Figure $4 \mathrm{~B})$, reduced the cell membrane damage $(p<0.05$; Figure $4 \mathrm{C})$, and obviously promoted cell survival (Figure 4D). miR-21-5p overexpression significantly reduced the expression of the direct targets of miR-21 [38], PTEN and PDCD-4, and the apoptosis marker gene caspase-3, conversely, enhanced expression of the anti-apoptotic gene Bcl-2 (Figure 4E). Similarly, upregulation of miR-378-3p robustly 
mitigated hypoxia-induced cell damage (Figure S2A-E). Consistent with previous research [36,38], our results suggest that upregulation of miR-21-5p and miR-378-3p mitigated hypoxia-induced apoptosis and enhanced cell viability, thereby supporting adaptation of the cell to the hypoxic conditions.
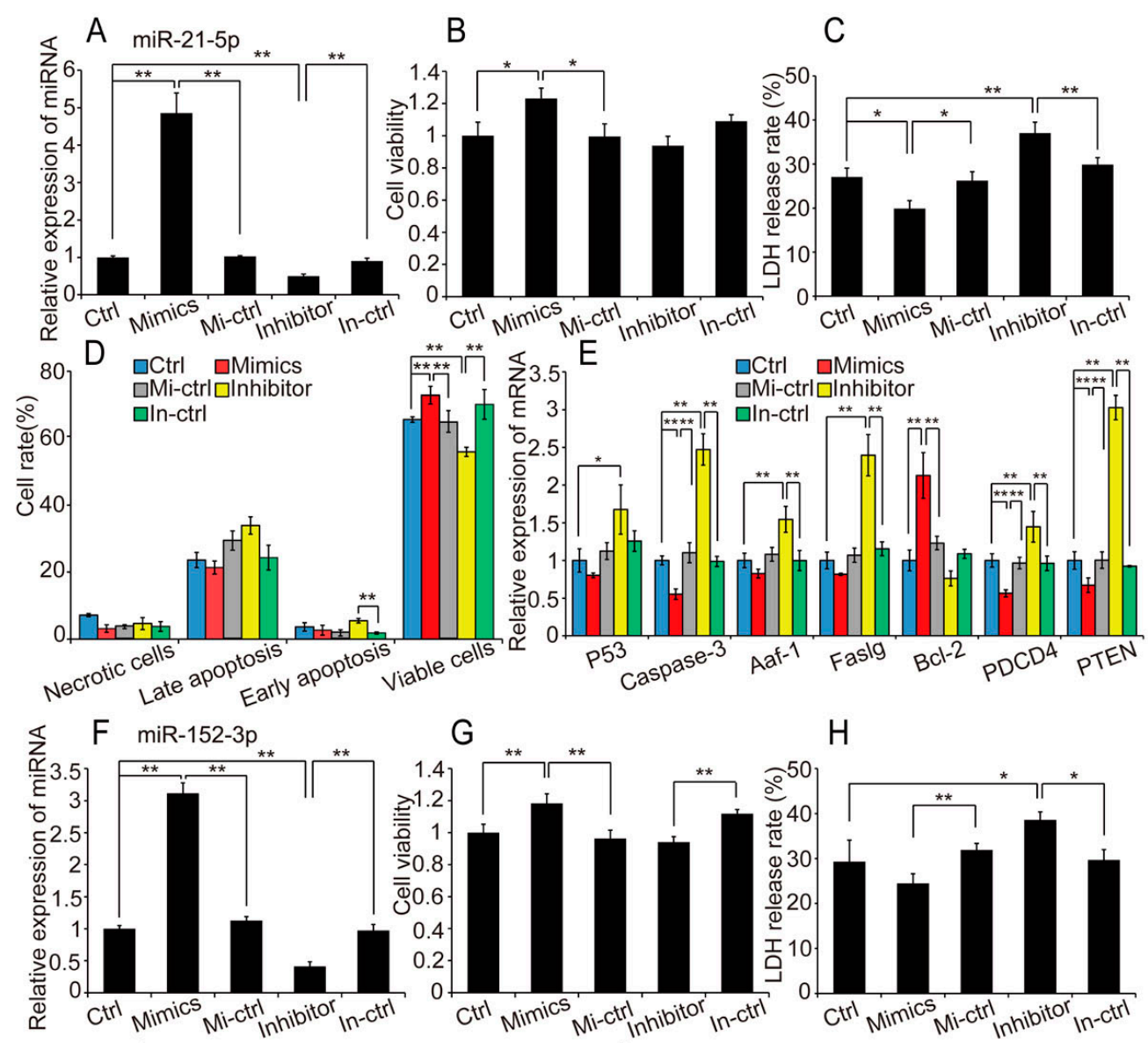

G
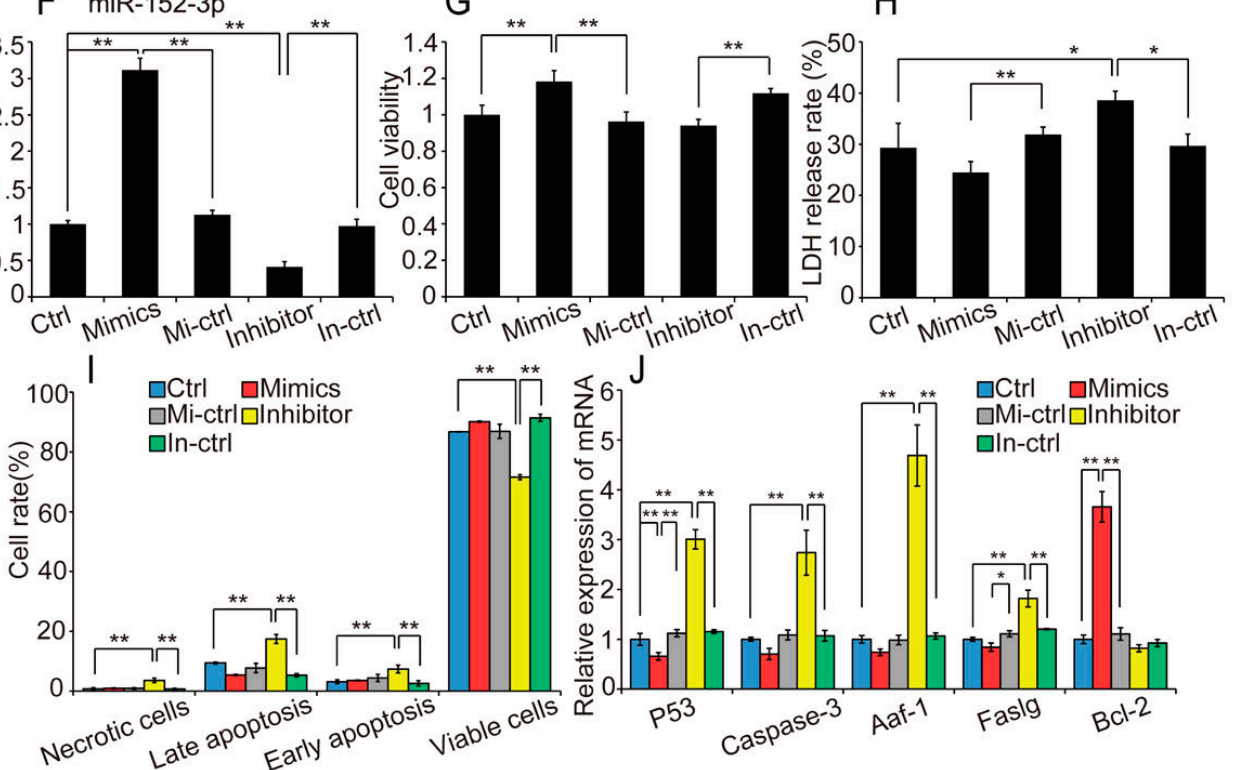

Figure 4. Overexpression of exosomal miRNA mitigates hypoxia-induced apoptosis. (A) Relative miRNA expression levels in control and miR-21-5p mimic- and inhibitor-transfected H9c2 cells; cells were exposed to hypoxia for $48 \mathrm{~h}$ after transfection; cell viability (B), membrane integrity (C) and apoptosis rate (D) were evaluated by CCK8, flow cytometry analysis and LDH release assay, respectively; expression levels of apoptosis-related genes and known target genes of miR-21-5p (PTEN and PDCD4) were measured by qRT-PCR (E); similarly, H9c2 cells were exposed to hypoxia $48 \mathrm{~h}$ after transfection with miR-152-3p and transfection efficiency (F); cell viability (G), membrane integrity $(\mathbf{H})$, apoptosis rate (I) and apoptosis-related gene expression $(\mathrm{J})$ were measured. "Ctrl", "Mi-ctrl" and "In-ctrl" represented "control", "mimics control", and "inhibitor control", respectively. Three independent experiments performed in triplicate and all data are expressed as mean \pm SD. ${ }^{*} p<0.05,{ }^{* *} p<0.01$. 
Based on these findings, we focused on miR-152-3p and let-7i-5p for further study. We first transfected H9c2 cells with miRNA mimic (or mimic control), or inhibitor (or inhibitor control). Transfection efficiency is shown in Figure 4F. The experimental treatment and detection methods were similar to those described above. We found that miR-152-3p attenuated the reduction in cell viability $(p<0.01)$ and the increase in cell membrane damage $(p<0.05)$ induced by hypoxia in H9c2 cells (Figure 4G,H). Although the suppression of cell apoptosis induced by miR-152-3p upregulation was not significant $(p=0.056)$, miR-152-3p inhibition significantly reduced cell viability $(p<0.01)$ and increased rates of apoptosis and necrosis, which supports an anti-apoptotic effect of miR-152-3p (Figure 4I). Additionally, pro-apoptotic genes including Caspase-3 and Faslg were inhibited by upregulation of miR-152-3p (Figure 4J). Similarly, let-7i-5p overexpression strongly reduced hypoxia-induced cell damage, including a reduction in cell membrane damage $(p<0.01)$ and apoptosis rate $(p<0.01)$, and downregulation of apoptosis-related genes (Figure S2F-J). These results demonstrate that miR-152-3p and let-7i-5p resemble miR-21-5p and miR-378-3p, which are highly expressed in hypoxic $\mathrm{H} 9 \mathrm{c} 2$ cells-derived exosomes, and have anti-apoptotic and pro-viability effects in H9c2 cells under hypoxic stress.

\subsection{Atg12 and Faslg Are Targets of miR-152-3p and Let-7i-5p, Respectively}

To explore the mechanism through which miR-152-3p and let-7i-5p mitigate hypoxia-induced H9c2 cells apoptosis, we predicted potential targets of miR-152-3p and let-7i-5p based on TargetScan and RNA hybrid analyses [39,40]. Atg12 and Faslg were predicted as putative targets of miR-152-3p and let-7i-5p, respectively. Atg12 encodes autophagy protein 12, a positive mediator of mitochondrial apoptosis that directly regulates the apoptotic pathway by binding and inactivating anti-apoptotic Bcl-2 family members, including Bcl-2 [41]. Faslg encodes Fas ligand, a member of the TNF family and the main activator of the extrinsic apoptotic pathway that binds the TNF receptor to induce apoptosis through the death-inducing signalling complex during heart failure [42], ischemia, and myocardial infarction [43]. Atg12 and Faslg mRNA levels were reduced when miR-152-3p and let-7i-5p were overexpressed in hypoxic $\mathrm{H} 9 \mathrm{c} 2$ cells (Figure 5A,B).

Bioinformatic prediction suggested that the $3^{\prime}$-UTR of Atg12 mRNA has one unique putative binding site for the miR-152-3p seed sequence (Figure 5C). We constructed a dual luciferase report plasmid (pmirGLO-Atg12 3'-UTR) encoding the rat Atg12 3'-UTR that contains miR-152-3p binding sites. This reporter plasmid (with wild-type [Wt] or mutant [Mut] Atg12 3'-UTR) was co-transfected with miR-152-3p mimic into HeLa cells, and luciferase activity assay was performed $48 \mathrm{~h}$ after transfection. Upregulation of miR-152-3p significantly repressed luciferase activity in HeLa cells transfected with the wild-type Atg12 3'-UTR reporter (0.74-fold change, $p=0.017$; Figure 5D), whereas this repression was completely abolished when the miR-152-3p binding site in Atg12 was mutated. This indicates that miR-152-3p inhibited Atg12 expression by binding the 3'-UTR. Similarly, cotransfection of pmirGLO-Faslg 3'-UTR (with Wt or Mut Faslg $3^{\prime}$-UTR) and let-7i-5p mimic into HeLa cells demonstrated that let-7i-5p was capable of targeting the $3^{\prime}$-UTR of Faslg mRNA (0.79-fold change in luciferase activity, $p=0.016$; Figure 5E). These results indicate that Atg12 and Faslg are the respective targets of miR-152-3p and let-7i-5p. miR-152-3p directly targeted Atg12 and activated the anti-apoptotic gene $B c l-2$, thus attenuating hypoxia-induced $\mathrm{H} 9 \mathrm{c} 2$ cells apoptosis [41]; simultaneously, let-7i-5p played an anti-apoptotic role by inhibiting Faslg and, thus, attenuating the cell death-inducing signalling cascade [42,43].

Exosomes, which contain a spectrum of bioactive molecules including proteins, RNA, and lipids, have emerged as key mediators of intercellular communication [44]. Most cardiac cell types, including cardiomyocytes, cardiac fibroblasts, and cardiac progenitor cells, have been demonstrated to release exosomes that play an important role in improving cardiac function [22,45]. Recent reports have indicated that exosomes isolated from the blood have a cardioprotective effect, mitigating I/R injury [46], and that cross-species transfer of this cardioprotective effect is possible, with plasma from preconditioned pigs ameliorating I/R injury in rats [47]. In this study, we found that exosomes derived 
from H9c2 cells under hypoxic stress contained large amounts of cardioprotective miRNAs, which mitigated hypoxia-induced $\mathrm{H} 9 \mathrm{c} 2$ cells apoptosis. We tentatively speculate a possible mechanism whereby, under hypoxic stress, hypoxia-sensitized H9c2 cells secrete and deliver hypoxamiR-enriched exosomes to surrounding cells to mitigate hypoxia-induced apoptosis and improve adaptation of the recipient cells to hypoxia. More specifically, we demonstrated for the first time that miR-152-3p and let-7i-5p, which were enriched in exosomes derived from $\mathrm{H} 9 \mathrm{c} 2$ cells under hypoxic conditions, played an anti-apoptotic role via the mitochondrial (intrinsic) and the death receptor (extrinsic) pathways, respectively.
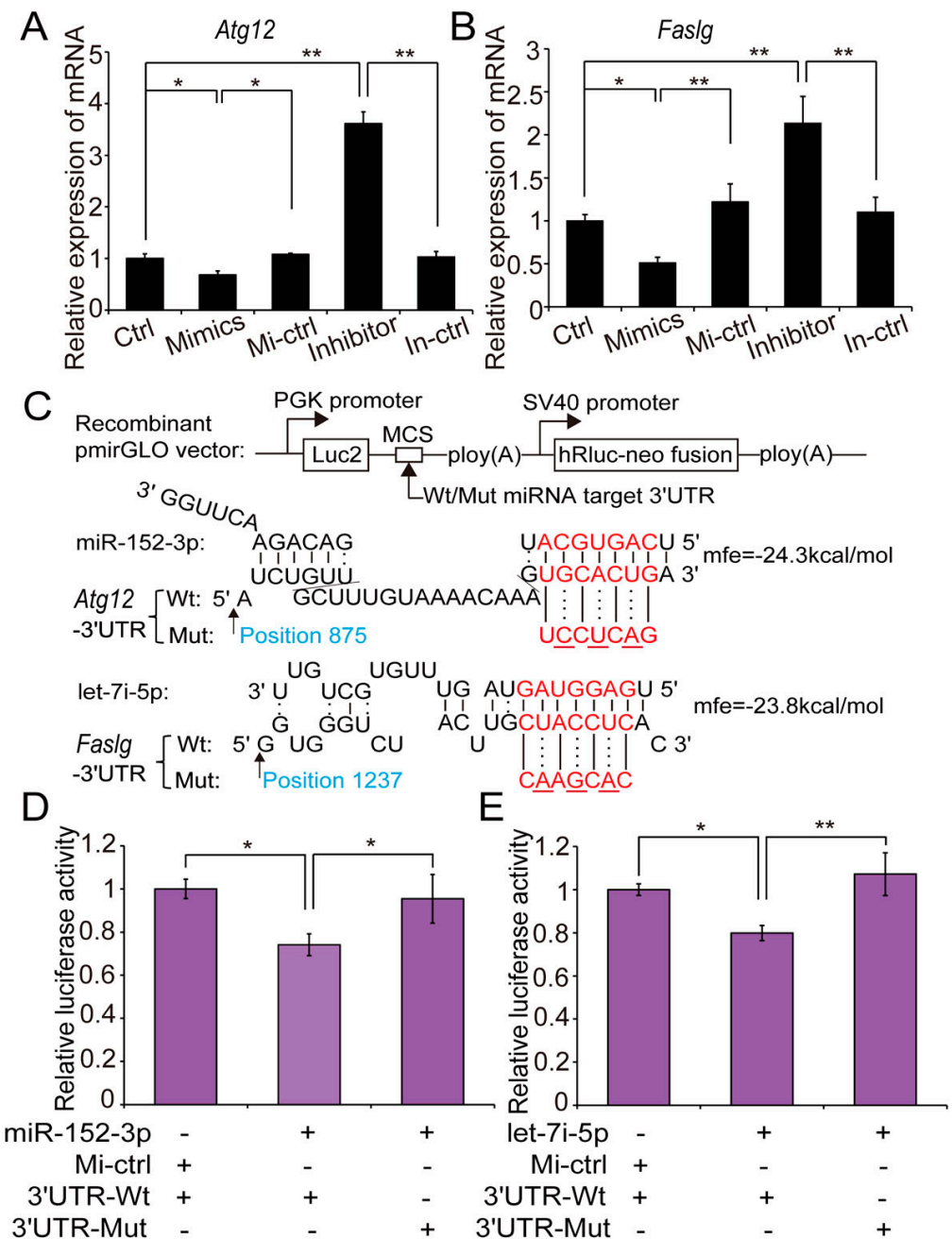

Figure 5. H9c2 cells-derived exosomal miRNAs exerted pro-viability effects by inhibiting apoptotic pathways. (A) Relative expression levels of Atg12 mRNA after gain- and loss-of-function miR-152-3p transfection experiments, determined by qRT-PCR; the qRT-PCR data are normalized to GAPDH; (C) potential binding sites for miR-152-3p in the 3'-UTR of Atg12 mRNA predicted by TargetScan, and the $3^{\prime}$-UTR Atg12 mutation used in our study. A luciferase reporter assay was performed by co-transfecting a luciferase reporter containing the $3^{\prime}$-UTR of Atg12 (wild-type [Wt] or mutant [Mut]) with a miR-152-3p mimic or control into HeLa cells; luciferase activity was determined $48 \mathrm{~h}$ after transfection (D); relative expression levels of Faslg mRNA after gain- and loss-of-function let-7i-5p transfection experiments (B); potential binding sites for let-7i let-7i-5p (C) and luciferase activity (E). "Ctrl", "Mi-ctrl", and "In-ctrl" represented "control", "mimics control", and "inhibitor control", respectively. Three independent experiments performed in triplicate and all data are expressed as means \pm SD. ${ }^{*} p<0.05,{ }^{* *} p<0.01$. 


\section{Materials and Methods}

\subsection{Cell Culture and Hypoxia Treatment}

The rat cardiomyoblast cell line (H9c2) was obtained from the cell bank of the Chinese Academy of Sciences and cultured in DMEM medium (Hyclone, Logan, UT, USA) supplemented with $10 \%$ exosome-depleted FBS prepared by ultracentrifugation at $160,000 \times \mathrm{g}$ at $4{ }^{\circ} \mathrm{C}$ for $16 \mathrm{~h}$ (Beckman, Brea, CA, USA). Normoxic cells were cultured in a humidified atmosphere of $95 \%$ air and $5 \% \mathrm{CO}_{2}$ at $37^{\circ} \mathrm{C}$; The cells were subjected to hypoxic conditions for $48 \mathrm{~h}$ when they reached approximately $50 \%$ confluency. Hypoxic cells were cultured in the hypoxic chamber using AnaeroPack (Mitsubishi Gas Company, Tokyo, Japan) to mimic a hypoxic environment in vitro, with other conditions consistent with those of the normoxic cells. The AnaeroPack started to absorb oxygen within 1 min, oxygen tension inside the chamber dropped to $1 \mathrm{mmHg}$ within $1 \mathrm{~h}\left(\mathrm{O}_{2}<1 \%, \mathrm{CO}_{2} \approx 5 \%\right)$ [48].

\subsection{Exosome Isolaton}

Exosomes were isolated from the conditioned medium of $\mathrm{H} 9 \mathrm{c} 2$ cells by several centrifugation and filtration steps, as described previously [12,49], with some modifications. Briefly, $10 \mathrm{~mL}$ of conditioned medium were centrifuged at $300 \times g$ for $10 \mathrm{~min}$, then at $2000 \times g$ for $10 \mathrm{~min}$ to remove cells and cellular debris; subsequently, the supernatant was further centrifuged at $10,000 \times g$ for 30 min at $4{ }^{\circ} \mathrm{C}$ and filtered through a $0.22-\mu \mathrm{m}$ filter to remove subcellular structures. Finally, exosomes pellet were collected by ultracentrifugation at $160,000 \times g$ for $70 \mathrm{~min}$. For further purification, the pellet were washed with PBS and centrifuged at $160,000 \times g$ for $70 \mathrm{~min}$. The pellet was resuspended in $250 \mu \mathrm{L}$ PBS, then immediately stored at $-80{ }^{\circ} \mathrm{C}$ until use.

\subsection{Nanoparticle Tracking Analysis}

Nanoparticle tracking analysis (NTA) permits determination of both the size distribution and relative concentration of nanoparticles, by recording laser light scattered by particles in solution undergoing Brownian motion and, thus, tracking particle movement. Briefly, $300 \mu \mathrm{L}$ pellet resuspensions were loaded into the sample chamber of an LM10 unit (Nanosight Technology, London, UK) and measurements were performed with a 405-nm 65-mW laser and an EMCCD Andor Luca camera. The analysis settings were optimized and kept identical each sample, and each video was analysed to give the mean, mode, median, and estimated concentration for each particle size. Data were analysed with NTA 2.1 software [50,51].

\subsection{Small RNA Library Construction and Sequencing}

Total RNA from H9c2 cells and corresponding exosomes were extracted using Trizol Reagent (Invitrogen, Carlsbad, CA, USA), according to the manufacturer's instructions $(n=4)$. RNA quality was examined using an Agilent 2100 Bioanalyzer (Agilent Technologies, Redwood City, CA, USA). Small RNA-seq was conducted using an Illumina HiSeq 2500 platform (RiboBio, Guangzhou, China). Briefly, small RNA fractions ranging from 18 to 30 nucleotides were enriched from total RNA by 15\% Tris-borate-EDTA polyacrylamide gel electrophoresis. To construct a small RNA sequencing library, $3^{\prime}$ and $5^{\prime}$ adaptors were ligated with the unique small RNA fractions. Subsequently, the adaptor-ligated RNA fragments were reverse-transcribed and amplified by PCR, and then were sequenced. The raw sequencing data have been submitted to the NCBI GEO database (GSE90123).

\subsection{Prediction and Functional Annotation of Exosomal DE miRNA Targets}

To explore the potential functions of the exosomal DE miRNAs, we conducted target prediction and functional enrichment analysis using DIANA-mirPath (http:/ / www.microrna.gr/miRPathv3). DIANA-mirPath is a miRNA pathway analysis web-server, providing accurate statistics, while being able to accommodate advanced pipelines. mirPath can utilize predicted miRNA targets (in CDS or 
3'-UTR) provided by the DIANA-microT-CDS algorithm, or even experimentally-validated miRNA interactions derived from DIANA-TarBase. These interactions (predicted and/or validated) can be subsequently combined with sophisticated merging and meta-analysis algorithms.

\section{6. miRNA Transfection}

Based on our small RNA-seq results and bioinformatic prediction, we selected several miRNA to use to verify function, including miR-21-5p, miR-378-3p, miR-152-3p, and miR-let-7i-5p. The specific miRNA mimic and inhibitor were purchased from RIBOBIO (Guangzhou, China). H9c2 cells were transfected using Lipofectamine 2000 (Invitrogen) according to the manufacturer's instructions. In brief, cells were transfected when they reached $50 \%$ confluency. Five groups of cells were prepared: control (no transfection); mimic-transfected; mimic-transfected control (transfected with miRNA containing no sequence similarities to any reported rat gene sequence); inhibitor-transfected (transfected with a single RNA sequence exactly complementary to the specific miRNA mimic); and inhibitor-transfected control. Transfection complexes were prepared by a series of premixing steps according to the manufacturer's protocol, and were then added to the medium to a final concentration of $50 \mathrm{nM}$ (or $100 \mathrm{nM}$ in the inhibitor-transfected group). Six hours after transfection, the medium was replaced. All groups were then exposed to hypoxia treatment for $48 \mathrm{~h}$ until the following experiment.

\subsection{Detection of Viability and Cell Damage by CCK8 and LDH Release}

To evaluate $\mathrm{H} 9 \mathrm{c} 2$ cells survival and membrane integrity after exposure to hypoxia, cell viability and LDH release were measured by CCK8 and LDH Release Assay Kit (Beyotime Biotechnology, Shanghai, China), respectively. CCK8 could react with dehydrogenase in active cells to form formazan. At $1.5-2 \mathrm{~h}$ before analysis, $10 \mu \mathrm{L}$ CCK 8 was added to the medium of cells cultured in 96-well plates. Optical density was measured at $450 \mathrm{~nm}$ using a microplate reader (Thermo, Madrid, Spain). Cell viability is presented as a percentage of control absorbance (that of untransfected cells) after subtracting the background absorbance of cell-free culture medium. LDH activity in the culture medium was determined with a microplate reader (at $490 \mathrm{~nm}$ ) using an enzymatic rate method. LDH release rate was calculated as a percentage of the maximum enzymatic activity of a control sample.

\subsection{Flow Cytometry Analysis of Cell Apoptosis}

Cell apoptosis rates were detected by flow cytometry using an Annexin V apoptosis detection kit (BD Pharmingen, San Diego, CA, USA). PI (propidium iodide) is commonly used for identifying dead cells and is generally excluded from viable cells. AV (Annexin V-FITC) is a common marker of apoptosis because of its high affinity for phosphatidylserine, which is translocated from the inner to the outer leaflet of the plasma membrane early in apoptosis. After $48 \mathrm{~h}$ of hypoxia treatment, cells were trypsin-digested and collected by centrifugation at $1000 \times g$ for $5 \mathrm{~min}$. Each sample was double-stained for 10 min with AV and PI and then analyzed by flow cytometry. Cells stained with AV and PI or AV only were considered necrotic and apoptotic, respectively.

\subsection{Fluorescence Staining of H9c2 Cells with Hoechst 33342/PI}

Cells were washed twice with PBS then stained with Hoechst $33342(10 \mathrm{mg} / \mathrm{mL})$ for $10 \mathrm{~min}$. The cells were then washed with PBS again and stained with PI for $10 \mathrm{~min}$. Stained cells were imaged by fluorescence microscopy (Olympus, Tokyo, Japan).

\subsection{Dual-Luciferase Activity Assay}

The potentially targeted mRNA contained the specific miRNA binding sites (wild-type [Wt] or mutant [Mut]) were synthesized from TSINGKE (Chengdu, China). The sequences were cleaved using Sac I/Xho I and cloned into the pmirGLO plasmid (Promega Corporation, Madison, WI, USA) at the $3^{\prime}$-end of the firefly luciferase reporter (luc2) gene (Figure 5C). HeLa cells were cultured in 96-well 
plates, when the cell density reached about $80 \%$ confluence, recombinant pmirGLO vector with [Wt] or [Mut] co-transfected with miRNA mimics into cells by Lipofectamine3000 (Invitrogen). Cells were collected after $48 \mathrm{~h}$, dual-luciferase activity was measured using the Dual-Luciferase Reporter Assay System kit (Promega), according to the manufacturer's instructions.

\subsection{1. $q R T-P C R$}

Total RNA (including miRNA) was extracted with TRIzol Reagent (Invitrogen). mRNA and miRNA were reverse-transcribed respectively using PrimeScript RT reagent Kit with gDNA Eraser and Mir- $X^{\mathrm{TM}}$ miRNA First Strand Synthesis Kit (Takara, Dalian, China), following the manufacturer's recommendations. qPCR was performed using an SYBR Premix Ex Taq kit (Takara) and a CFX96 system (Bio-Rad, Hercules, CA, USA). All reactions were performed in triplicate. Relative expression levels of mRNAs and miRNAs were calculated using the $2^{-\triangle \Delta C t}$ method. GAPDH and U6 were used as housekeeping genes for normalizing mRNA and miRNA, respectively. Sequences of the primers used for qPCR are shown in Table S3.

\subsection{Statistical Analysis}

All data are expressed as mean \pm SD. Statistical significance was calculated by one way analysis of variance (ANOVA) with Tukey's post-hoc test for multiple groups or Student's $t$-test for comparisons of two groups, using SPSS 19.0 software (SPSS Inc., Chicago, IL, USA). $p<0.05$ was considered statistically significant $\left({ }^{*} p<0.05 ; * * 0.01\right)$.

\section{Conclusions}

In this study, we revealed the miRNAome of H9c2 cells and exosomes under both hypoxia and normoxia. We identified 331, 338, 144, and 74 unique mature miRNAs in hypoxic cells, normoxic cells, hypoxic exosomes, and normoxic exosomes, respectively. Moreover, we identified 92 and 62 DE miRNAs in cells and exosomes between hypoxia and normoxia, respectively. These exosomal DE miRNAs were mainly involved in the HIF-1 signaling pathway or pathways related to cell apoptosis, such as the TNF, MAPK, and mTOR pathways. Interestingly, we found that some exosomal DE miRNAs, including miR-21-5p, miR-378-3p, miR-152-3p, and let-7i-5p, had potential anti-apoptotic and pro-viability effects in $\mathrm{H} 9 \mathrm{c} 2$ cells under hypoxic stress. Additionally, we identified Atg12 and Faslg as the respective targets of miR-152-3p and let-7i-5p, which partly elucidates the anti-apoptotic mechanism of hypoxia-induced exosomal miRNA. In brief, our results reveal that exosomes derived from H9c2 cells in response to hypoxia loaded with large amounts of cardioprotective miRNAs and mitigate hypoxia-induced $\mathrm{H} 9 \mathrm{c} 2$ cells apoptosis, which may present a potential novel treatment for AMI and other types of heart disease.

Supplementary Materials: Supplementary materials can be found at www.mdpi.com/1422-0067/18/4/711/s1.

Acknowledgments: This work was supported by grants from the National High Technology Research and Development Program of China (863 Program) (2013AA102502), the National Special Foundation for Transgenic Species of China (2014ZX0800950B and 2014ZX08006-003), the National Natural Science Foundation of China (31601918, 31530073, 31522055, and 31472081), the Specialized Research Fund of Ministry of Agriculture of China (NYCYTX-009), the Program for Innovative Research Team of Sichuan Province (2015TD0012), the Key Project of Sichuan Education Department (16ZA0025, 15ZA0008, and 15ZA0003), the Earmarked Fund for China Agriculture Research System (No. CARS-36-01A), National Program for Support of Top-notch Young Professionals and the Young Scholars of the Yangtze River.

Author Contributions: Jinwei Zhang, Jideng Ma, Xuewei Li, and Mingzhou Li conceived and designed the study and drafted the manuscript. Keren Long, Wanling Qiu, Yujie Wang, Zihui Hu, Can Liu, and Yi Luo performed the experiments. Jinwei Zhang, Jideng Ma, Keren Long, Anan Jiang, Long Jin, Qianzi Tang, and Xun Wang analyzed all of the experiments. All authors read and approved the final manuscript.

Conflicts of Interest: The authors declare no conflict of interest. 


\section{Abbreviations}

$\begin{array}{ll}\text { DE miRNA } & \text { Differentially-Expressed miRNA } \\ \text { AMI } & \text { Acute Myocardial Infarction } \\ \text { HIF } & \text { Hypoxia-Inducible Factor } \\ \text { HRE } & \text { Hypoxia Response Elements } \\ \text { CPCs } & \text { Cardiac Progenitor Cells } \\ \text { CCK8 } & \text { Cell Counting Kit-8 } \\ \text { LDH } & \text { Lactate Dehydrogenase } \\ \text { NTA } & \text { Nanoparticle Tracking Analysis } \\ \text { FBS } & \text { Foetal Bovine Serum } \\ \text { PBS } & \text { Phosphate-Buffered Saline } \\ \text { AV } & \text { Annexin V-FITC } \\ \text { PI } & \text { Propidium Iodide }\end{array}$

\section{References}

1. Members, W.G.; Mozaffarian, D.; Benjamin, E.J.; Go, A.S.; Arnett, D.K.; Blaha, M.J.; Cushman, M.; Das, S.R.; De, F.S.; Després, J.P. Heart Disease and Stroke Statistics-2016 Update: A Report From the American Heart Association. Circulation 2015, 133, e38-360.

2. Santos-Gallego, C.G.; Picatoste, B.; Badimón, J.J. Pathophysiology of acute coronary syndrome. Curr. Atheroscler. Rep. 2014, 16, 401. [CrossRef] [PubMed]

3. Heusch, G. Molecular Basis of Cardioprotection Signal Transduction in Ischemic Pre-, Post-, and Remote Conditioning. Circ. Res. 2015, 116, 674-699. [CrossRef] [PubMed]

4. Jacobson, M.D.; Weil, M.; Raff, M.C.; Jacobson, M.D.; Weil, M.; Raff, M.C. Programmed Cell Death in Animal Development. Cell 1997, 88, 347-354. [CrossRef]

5. Jiang, B.H.; Rue, E.; Wang, G.L.; Roe, R.; Semenza, G.L. Dimerization, DNA binding, and transactivation properties of hypoxia-inducible factor 1. J. Biol. Chem. 1996, 271, 17771-17778. [CrossRef] [PubMed]

6. Semenza, G.L. Hypoxia-inducible factors in physiology and medicine. Cell 2012, 148, 399-408. [CrossRef] [PubMed]

7. Nallamshetty, S.; Chan, S.Y.; Loscalzo, J. Hypoxia: A master regulator of microRNA biogenesis and activity. Free Radic. Biol. Med. 2013, 64, 20-30. [CrossRef] [PubMed]

8. Greijer, A.E.; van de Wall, E. The role of hypoxia inducible factor 1 (HIF-1) in hypoxia induced apoptosis. J. Clin. Pathol. 2004, 57, 1009-1014. [CrossRef] [PubMed]

9. Bartel, D.P. MicroRNAs: Genomics, biogenesis, mechanism, and function. Cell 2004, 116, 281-297. [CrossRef]

10. Azzouzi, H.E.; Leptidis, S.; Doevendans, P.A.; De Windt, L.J. HypoxamiRs: Regulators of cardiac hypoxia and energy metabolism. Trends Endocrinol. Metab. 2015, 26, 502-508. [CrossRef] [PubMed]

11. Valadi, H.; Ekström, K.; Bossios, A.; Sjöstrand, M.; Lee, J.J.; Lötvall, J.O. Exosome-mediated transfer of mRNAs and microRNAs is a novel mechanism of genetic exchange between cells. Nat. Cell Biol. 2007, 9, 654-659. [CrossRef] [PubMed]

12. Bang, C.; Batkai, S.; Dangwal, S.; Gupta, S.K.; Foinquinos, A.; Holzmann, A.; Just, A.; Remke, J.; Zimmer, K.; Zeug, A. Cardiac fibroblast-derived microRNA passenger strand-enriched exosomes mediate cardiomyocyte hypertrophy. J. Clin. Investig. 2014, 124, 2136-2146. [CrossRef] [PubMed]

13. Wang, Y.; Zhang, L.; Li, Y.; Chen, L.; Wang, X.; Guo, W.; Zhang, X.; Qin, G.; He, S.H.; Zimmerman, A. Exosomes/microvesicles from induced pluripotent stem cells deliver cardioprotective miRNAs and prevent cardiomyocyte apoptosis in the ischemic myocardium. Int. J. Cardiol. 2015, 192, 61-69. [CrossRef] [PubMed]

14. Barile, L.; Lionetti, V.; Cervio, E.; Matteucci, M.; Gherghiceanu, M.; Popescu, L.M.; Torre, T.; Siclari, F.; Moccetti, T.; Vassalli, G. Extracellular vesicles from human cardiac progenitor cells inhibit cardiomyocyte apoptosis and improve cardiac function after myocardial infarction. Cardiovasc. Res. 2014, 103, 530-541. [CrossRef] [PubMed]

15. Saraste, A.; Pulkki, K.; Kallajoki, M.; Henriksen, K.; Parvinen, M.; Voipiopulkki, L.M. Apoptosis in human acute myocardial infarction. Circulation 1997, 95, 320-323. [CrossRef] [PubMed]

16. Bonavita, F.; Stefanelli, C.; Giordano, E.; Columbaro, M.; Facchini, A.; Bonafè, F.; Caldarera, C.M.; Guarnieri, C. H9c2 cardiac myoblasts undergo apoptosis in a model of ischemia consisting of serum deprivation and hypoxia: Inhibition by PMA. FEBS Lett. 2003, 536, 85-91. [CrossRef] 
17. Ekhterae, D.; Lin, Z.; Lundberg, M.S.; Crow, M.T.; Núñez, G. ARC inhibits cytochrome c release from mitochondria and protects against hypoxia-induced apoptosis in heart-derived H9c2 cells. Circ. Res. 1999, 85, 70-77. [CrossRef]

18. Hu, S.; Huang, M.; Li, Z.; Jia, F.; Ghosh, Z.; Lijkwan, M.A.; Fasanaro, P.; Sun, N.; Wang, X.; Martelli, F.; et al. MicroRNA-210 as a Novel Therapy for Treatment of Ischemic Heart Disease. Circulation 2010, 122, S124-S131. [CrossRef] [PubMed]

19. Zhao, R.; Qian, L.; Jiang, L. miRNA-dependent cross-talk between VEGF and Ang-2 in hypoxia-induced microvascular dysfunction. Biochem. Biophys. Res. Commun. 2014, 452, 428-435. [CrossRef] [PubMed]

20. Rane, S.; He, M.; Sayed, D.; Vashistha, H.; Malhotra, A.; Sadoshima, J.; Vatner, D.E.; Vatner, S.F.; Abdellatif, M. Downregulation of miR-199a derepresses hypoxia-inducible factor- $1 \alpha$ and Sirtuin 1 and recapitulates hypoxia preconditioning in cardiac myocytes. Circ. Res. 2009, 104, 879-886. [CrossRef] [PubMed]

21. Yuan, M.J.; Maghsoudi, T.; Wang, T. Exosomes Mediate the Intercellular Communication after Myocardial Infarction. Int. J. Med. Sci. 2016, 13, 113-116. [CrossRef] [PubMed]

22. Sluijter, J.P.; Verhage, V.; Deddens, J.C.; van den Akker, F.; Doevendans, P.A. Microvesicles and exosomes for intracardiac communication. Cardiovasc. Res. 2014, 102, 302-311. [CrossRef] [PubMed]

23. Beninson, L.A.; Fleshner, M. Exosomes: An emerging factor in stress-induced immunomodulation. Semin. Immunol. 2014, 26, 394-401. [CrossRef] [PubMed]

24. Sano, S.; Izumi, Y.; Yamaguchi, T.; Yamazaki, T.; Tanaka, M.; Shiota, M.; Osada-Oka, M.; Nakamura, Y.; Wei, M.; Wanibuchi, H.; et al. Lipid synthesis is promoted by hypoxic adipocyte-derived exosomes in 3T3-L1 cells. Biochem. Biophys. Res. Commun. 2014, 445, 327-333. [CrossRef] [PubMed]

25. Garcia, N.A.; Ontoria-Oviedo, I.; González-King, H.; Diez-Juan, A.; Sepúlveda, P. Glucose Starvation in Cardiomyocytes Enhances Exosome Secretion and Promotes Angiogenesis in Endothelial Cells. PLoS ONE 2015, 10, e0138849. [CrossRef] [PubMed]

26. Gray, W.D.; French, K.M.; Ghoshchoudhary, S.; Maxwell, J.T.; Brown, M.E.; Platt, M.O.; Searles, C.D.; Davis, M.E. Identification of therapeutic covariant microRNA clusters in hypoxia-treated cardiac progenitor cell exosomes using systems biology. Circ. Res. 2015, 116, 255-263. [CrossRef] [PubMed]

27. Vlachos, I.S.; Zagganas, K.; Paraskevopoulou, M.D.; Georgakilas, G.; Karagkouni, D.; Vergoulis, T.; Dalamagas, T.; Hatzigeorgiou, A.G. DIANA-miRPath v3.0: Deciphering microRNA function with experimental support. Nucleic Acids Res. 2015, 43, 460-466. [CrossRef] [PubMed]

28. Haudek, S.B.; Taffet, G.E.; Schneider, M.D.; Mann, D.L. TNF provokes cardiomyocyte apoptosis and cardiac remodeling through activation of multiple cell death pathways. J. Clin. Investig. 2007, 117, 2692-2701. [CrossRef] [PubMed]

29. Krown, K.A.; Page, M.T.; Nguyen, C.; Zechner, D.; Gutierrez, V.; Comstock, K.L.; Glembotski, C.C.; Quintana, P.J.; Sabbadini, R.A. Tumor necrosis factor alpha-induced apoptosis in cardiac myocytes. Involvement of the sphingolipid signaling cascade in cardiac cell death. J. Clin. Investig. 2011, 98, 2854-2865. [CrossRef] [PubMed]

30. Chang, L.; Karin, M. Mammalian MAP kinase signaling cascades. Nature 2001, 410, 37-40. [CrossRef] [PubMed]

31. Tobiume, K.; Matsuzawa, A.; Takahashi, T.; Nishitoh, H.; Morita, K.I.; Takeda, K.; Minowa, O.; Miyazono, K.; Noda, T.; Ichijo, H. ASK1 is required for sustained activations of JNK/p38 MAP kinases and apoptosis. EMBO Rep. 2001, 2, 222-228. [CrossRef] [PubMed]

32. Ma, X.L.; Kumar, S.; Gao, F.; Louden, C.S.; Lopez, B.L.; Christopher, T.A.; Wang, C.; Lee, J.C.; Feuerstein, G.Z.; Yue, T.L. Inhibition of p38 mitogen-activated protein kinase decreases cardiomyocyte apoptosis and improves cardiac function after myocardial ischemia and reperfusion. Circulation 1999, 99, 1685-1691. [CrossRef] [PubMed]

33. Lu, Z.; Xu, S. ERK1/2 MAP kinases in cell survival and apoptosis. IUBMB Life 2006, 58, 621-631. [CrossRef] [PubMed]

34. Santos-Gallego, C.G.; Vahl, T.P.; Goliasch, G.; Picatoste, B.; Arias, T.; Ishikawa, K.; Njerve, I.U.; Sanz, J.; Narula, J.; Sengupta, P.P.; et al. Sphingosine-1-Phosphate Receptor Agonist Fingolimod Increases Myocardial Salvage and Decreases Adverse Postinfarction Left Ventricular Remodeling in a Porcine Model of Ischemia/Reperfusion. Circulation 2016, 133, 954-966. [CrossRef] [PubMed]

35. Castedo, M.; Ferri, K.F.; Kroemer, G. Mammalian target of rapamycin (mTOR): Pro- and anti-apoptotic. Cell Death Differ. 2002, 9, 99-100. [CrossRef] [PubMed] 
36. Fang, J.; Song, X.W.; Tian, J.; Chen, H.Y.; Li, D.F.; Wang, J.F.; Ren, A.J.; Yuan, W.J.; Lin, L. Overexpression of microRNA-378 attenuates ischemia-induced apoptosis by inhibiting caspase-3 expression in cardiac myocytes. Apoptosis 2012, 17, 410-423. [CrossRef] [PubMed]

37. Cheng, Y.H.; Zhu, P.; Yang, P.; Liu, X.J.; Dong, S.M.; Wang, X.B.; Chun, B.; Zhuang, J.; Zhang, C.X. Ischaemic preconditioning-regulated miR-21 protects heart against ischaemia/reperfusion injury via anti-apoptosis through its target PDCD4. Cardiovasc. Res. 2010, 87, 431-439. [CrossRef] [PubMed]

38. Buscaglia, L.E.; Li, Y. Apoptosis and the target genes of microRNA-21. Chin. J. Cancer 2011, 30, 371-380. [CrossRef] [PubMed]

39. Mazière, P.; Enright, A.J. Prediction of microRNA targets. Drug Discov. Today 2007, 12, 452-458. [CrossRef] [PubMed]

40. Krüger, J.; Rehmsmeier, M. RNAhybrid: MicroRNA target prediction easy, fast and flexible. Nucleic Acids Res. 2006, 34, 451-454. [CrossRef] [PubMed]

41. Rubinstein, A.D.; Eisenstein, M.; Ber, Y.; Bialik, S.; Kimchi, A. The autophagy protein Atg12 associates with antiapoptotic Bcl-2 family members to promote mitochondrial apoptosis. Mol. Cell 2011, 44, 698-709. [CrossRef] [PubMed]

42. Setsuta, K.; Seino, Y.; Ogawa, T.; Ohtsuka, T.; Seimiya, K.; Takano, T. Ongoing myocardial damage in chronic heart failure is related to activated tumor necrosis factor and Fas/Fas ligand system. Circ. J. 2004, 68, 747-750. [CrossRef] [PubMed]

43. Lee, P.; Sata, M.; Lefer, D.J.; Factor, S.M.; Walsh, K.; Kitsis, R.N. Fas pathway is a critical mediator of cardiac myocyte death and MI during ischemia-reperfusion in vivo. Am. J. Physiol. Heart C 2003, 284, H456-H463. [CrossRef] [PubMed]

44. Barile, L.; Moccetti, T.; Marbán, E.; Vassalli, G. Roles of exosomes in cardioprotection. Eur. Heart J. 2016. [CrossRef] [PubMed]

45. Sahoo, S.; Losordo, D.W. Exosomes and Cardiac Repair After Myocardial Infarction. Circ. Res. 2014, 114, 333-344. [CrossRef] [PubMed]

46. Vicencio, J.M.; Yellon, D.M.; Sivaraman, V.; Das, D.; Boi-Doku, C.; Arjun, S.; Zheng, Y.; Riquelme, J.A.; Kearney, J.; Sharma, V. Plasma exosomes protect the myocardium from ischemia-reperfusion injury. J. Am. Coll. Cardiol. 2015, 65, 1525-1536. [CrossRef] [PubMed]

47. Skyschally, A.; Gent, S.; Amanakis, G.; Schulte, C.; Kleinbongard, P.; Heusch, G. Across-Species Transfer of Protection by Remote Ischemic Preconditioning With Species-Specific Myocardial Signal Transduction by Reperfusion Injury Salvage Kinase and Survival Activating Factor Enhancement Pathways Novelty and Significance. Circ. Res. 2015, 117, 279-288. [CrossRef] [PubMed]

48. Yamamoto, Y.; Osanai, T.; Nishizaki, F.; Sukekawa, T. Matrix metalloprotein-9 activation under cell-to-cell interaction between endothelial cells and monocytes: Possible role of hypoxia and tumor necrosis factor- $\alpha$. Heart Vessels 2012, 27, 624-633. [CrossRef] [PubMed]

49. Soares, A.R.; Martinsmarques, T.; Ribeirorodrigues, T.; Ferreira, J.V.; Catarino, S.; Pinho, M.J.; Zuzarte, M.; Anjo, S.I.; Manadas, B.; Sluijter, J.P.G.; et al. Gap junctional protein Cx43 is involved in the communication between extracellular vesicles and mammalian cells. Sci. Rep. 2015, 5, 13243. [CrossRef] [PubMed]

50. Soo, C.Y.; Song, Y.; Zheng, Y.; Campbell, E.C.; Riches, A.C.; Gunnmoore, F.; Powis, S.J. Nanoparticle tracking analysis monitors microvesicle and exosome secretion from immune cells. Immunology 2012, 136, 192-197. [CrossRef] [PubMed]

51. Livshts, M.A.; Khomyakova, E.; Evtushenko, E.G.; Lazarev, V.N.; Kulemin, N.A.; Semina, S.E.; Generozov, E.V.; Govorun, V.M. Isolation of exosomes by differential centrifugation: Theoretical analysis of a commonly used protocol. Sci. Rep. 2015, 6, 21447. [CrossRef] [PubMed]

(C) 2017 by the authors. Licensee MDPI, Basel, Switzerland. This article is an open access article distributed under the terms and conditions of the Creative Commons Attribution (CC BY) license (http:/ / creativecommons.org/licenses/by/4.0/). 